\title{
The Specifics of Use of Composite Materials in Consolidation of Historical Monuments
}

\author{
Vlăescu Daniel, Djordje Krkljus, Dogaru Petrișor
}

\begin{abstract}
The use of composite systems in protecting, preserving and maintaining historical monuments has become more and more used. There are several consolidation procedures with fiber-reinforced polymeric polymers that can be applied as required or on the basis of the basic material (concrete, masonry, wood, etc.). Besides the many advantages it provides, the application of composite systems in the rehabilitation of heritage buildings and historical monuments requires minimal workmanship. More and more cities are actively involved in the rehabilitation and preservation of heritage buildings and historical monuments by launching good practice guides to preserve local cultural heritage by applying composite elements as robust as possible without the need to modify the overall dimensions of the buildings through a classic covering.
\end{abstract}

Keywords - composite materials, consolidation, historical monuments.

\section{INTRODUCTION}

Protecting and preserving historical monuments and heritage buildings has been and is a priority for the civilization of any people. Preservation, rehabilitation and restoration of buildings nowadays are the main areas of urban and architectural practice.

When it is realized that a historic heritage building requires consolidation, rehabilitation or repair work, in the vast majority of cases, it is recommended to use materials that are similar to those of traditional original materials, such as: carved or cast stone, wood, terracotta, cast iron, iron, concrete, etc. In case of necessity to replace parts or elements of a historical building, the replacement material should have similar characteristics in terms of appearance, structure, color or other attributes of the same nature as original material.

Taking into account the technological progress of the last decades and due to the noninvasive intervention of the composite elements, increasingly more synthetically produced materials of epoxy resins type, polymers and fiber-reinforced composite materials have begun to be used for protection, preservation and maintenance of historical monuments.

From the current practice, it is possible to notice a fact that a small part of the materials cannot be changed during the rehabilitation process. The vast majority of materials can be totally or partially replaced within the framework of restoration and consolidation of buildings with materials such as: stone, wood, concrete, fiber reinforced concrete, polymer composites, etc. 


\section{sciendo $_{26}$}

26 Ovidius University Annals Series: Civil Engineering, Year 21, 2019

In order to be able to replace original building materials with composite materials, it is necessary to meet certain minimum requirements:

- to be durable in time,

- to be at least similar to the original ones;

- to be compatible with other original building materials;

Damage to historical monuments and heritage buildings is caused by exposure to climatic and external factors and/or multiple causes of degradation. In addition to accidental causes (fire, earthquake, war), the causes of degradation can be divided into: chemical, biological, physical or mechanical.

The effects of chemical degradation are mainly due to two phenomena:

- the reaction of the sulphate which is present in the masonry with calcium hydrosulphates and hydroaluminates. These are very intense due to the frequency of exposed stone and brick masonry;

- the reaction of alkali substances contained in binders and present in the sand of masonry mortar and in aggregates.

Mechanical type degradation effects are due to the stresses caused by loads before and after construction, loads due to traffic growth, equipment and machinery loads, etc.

Biological type degradation effects are due to the formation and appearance of some algae and vegetal formations in the wet areas of masonry.

Physical type degradation effects are related in the vast majority of cases to temperature variations.

\section{ASPECTS REGARDING THE CONSOLIDATION OF HISTORICAL MONUMENTS WITH COMPOSITE MATERIALS COMPARED TO TRADITIONAL MATERIALS}

For the protection and maintenance of historical monuments and heritage buildings, there are several classical methods applied such as: repairing with concrete seals the walls of the load-bearing walls, retailing the cracks of masonry areas by removing the joints between the elements, by replacing the damaged elements by inserting steel clips for fixing the masonry, repairing with reinforcing steel bars, by injection of cement mortars in the masonry, reinforcing the masonry walls with reinforced concrete piles and belts and reinforcing concrete.

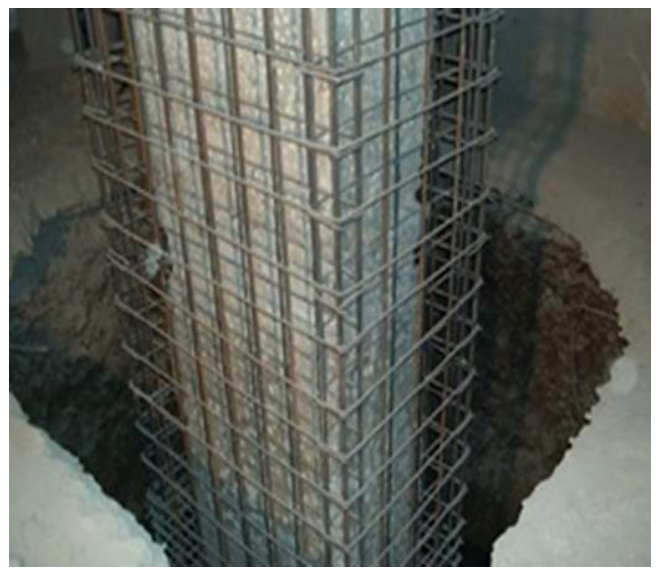

Fig. 1 Classical consolidation

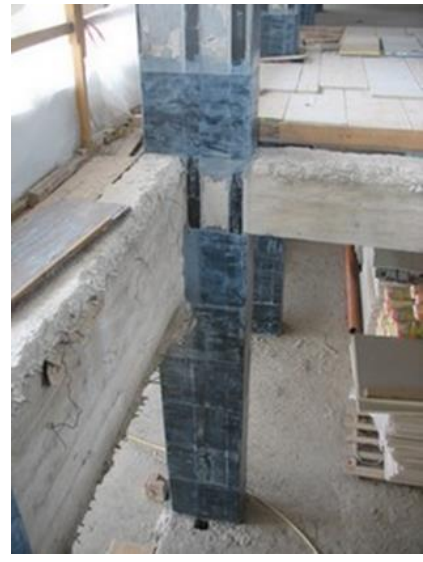

Fig. 2 Consolidation with composite systems 
For the repair of historical monuments, modern methods of consolidation by means of shielding with fiber-reinforced polymeric composites are used lately due to the advantages offered by them. The main methods applied are: pre-tensioning and post-tensioning with polymerized composite strips systems, confinement with fiber-reinforced polymer composites, embedded composite bars and anchoring with fiber-reinforced polymer composites.

The vast majority of fiber-reinforced polymer composite products are compatible with traditional materials such as wood, steel, concrete or aluminum.

Solution for historic monument or heritage building consolidation is chosen on the basis of meticulous analysis, and the favorable result at the end of the project is provided by involvement of a professional team of architects, engineers, contractors, manufacturers, etc. but also by complying the laws and regulations in force.

Depending on the architecture and the use of the monument, there are a number of specific rules and conditions of maintenance and exploitation. The use, operation and maintenance of heritage buildings and monuments shall be carried out in compliance with Law no. 422/2001 regarding the protection of historical monuments and the obligations regarding their use. Patrimony building structure must be checked periodically, and in the case of damage, intervention should take place as soon as possible.

Legislation on the protection of historical monuments refers to a number of rules and principles regarding the interventions of the owners, concessionaires, holders of the right of administration and the tenants on the historical monuments in order to guarantee the preservation, restoration, consolidation, as well as other works. The specialized works must be performed only by the persons certified for this purpose and only after stipulation in the execution contracts of the conditions and terms of execution included in the expert opinion.

Practical experience has shown that the modern rehabilitation techniques can be used to conserve historical monuments. In order to be sure of the success of the rehabilitation process of a monument, adequate structural intervention is required, which will be determined by a certified expert on the basis of building's conditions, the spatial dimensions, the climate and the technical aspects encountered. Interventions in the preservation and restoration of the monument must be accompanied by exact documentation, analytical reports, drawings, photographs, etc.

The certified designer will decide on which affected surfaces the composite elements will be applied, whether it is continuous fabric or strips, or it is the anchoring of composite products. In any case, it is recommended that the composite fibers to be aligned to direction of the main tension stresses.

Fiber-reinforced polymeric composites contribute to increased shear strength which can be determined by several factors (composite stiffness, resin quality, support of the backing layer) and have a number of advantages over traditional materials, such as:

- fire resistance due to reduced thermal conductivity;

- due to their low weight, they can be applied to buildings where the foundation cannot be additionally loaded;

- reduced execution time;

- the minimum maintenance cost;

- possibility of pretensioning by increasing shear stress capacity;

- high resistance;

- reduced transport costs due to lower fiber weight;

- easier preparation of contact surfaces;

- easier and simpler to fit;

- durability;

- low frost-thaw risk; 
- flexibility in designing;

- not magnetic material.

Fiber reinforced polymeric composites have the following disadvantages:

- Relatively high cost;

- Qualified staff are required for application;

- Some resins require special treatment for toxicity.

\section{SOLUTIONS FOR CONSOLIDATION OF CONCRETE HERITAGE STRUCTURES}

It is well known fact that for more than two decades concrete structures can be reinforced with composite systems. Due to the wide range of applicability, composite systems have also been used to protect and preserve concrete historic monuments and heritage buildings.

The essential reason why a concrete structure requiring consolidation needs to be analyzed is given by the knowledge of the causes, effects and mechanisms of deterioration. The deterioration in time of reinforced concrete or simple concrete is exerted by several destructive factors and due to external causes, such as wear, attack of chemicals, temperature variation. Internal causes of permeability, incompatibility between cement and aggregates, etc., as well as the causes of deterioration over time due to: reinforcement and concrete corrosion, gelling, erosion, cracking, etc., must not be neglected.

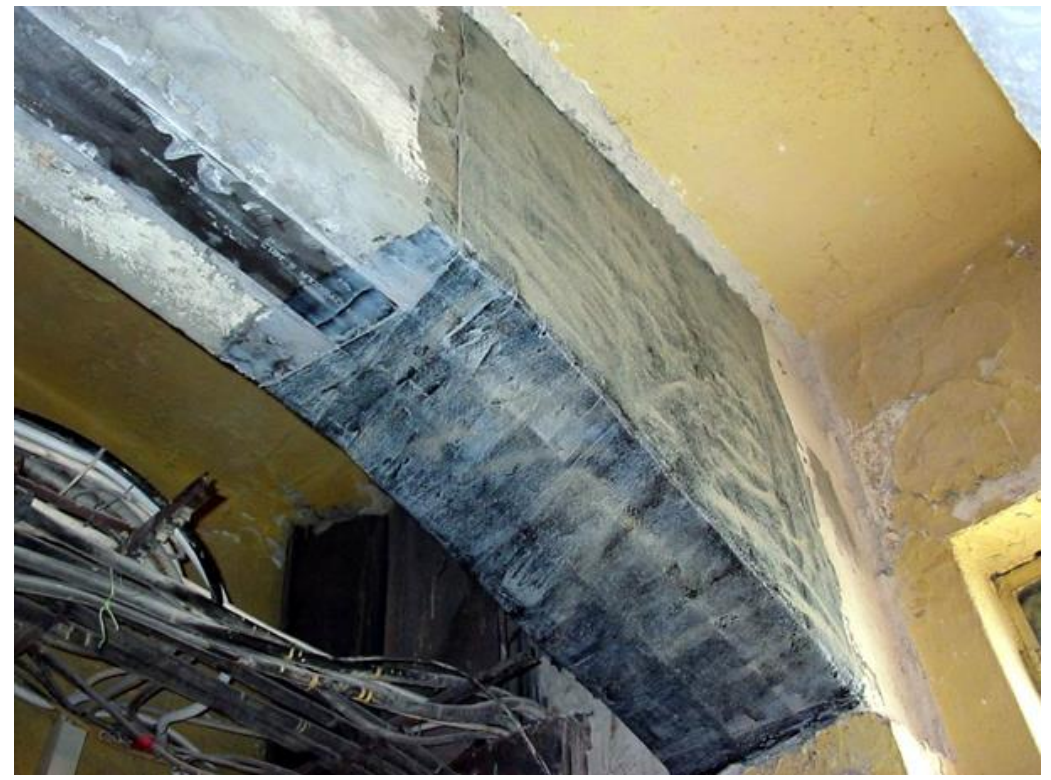

Fig. 3 Example of structural rehabilitation

Successful consolidation solutions have been used with composite systems in concrete heritage structures, especially at:

- consolidation of beams and deformed slabs due to bending;

- consolidation of beams and columns deteriorated due to shear forces;

- confinement consolidation of the pillars;

- structural consolidation of framework nodes. 
Composite system consolidation solutions can be obtained by combining several types of polymer fibers and matrices. For consolidation of the concrete structures, the most used composite systems are provided by the combination of reinforcements (glass, carbon, aramid, etc.) and matrix (epoxy resin, polyester, vinyl ester, etc.).

\section{CONSOLIDATION SOLUTIONS FOR MASONRY HERITAGE STRUCTURES}

Due to the remarkable results obtained from the use of composite systems in masonry consolidation, the consolidation solution for reinforced composite patrimony structures has been implemented in a much wider context. Considering the fact that the vast majority of historical monuments and heritage buildings are built from masonry, rehabilitation with composite systems has been possible due to the fact that some traditional solutions have some inconveniences and disadvantages, such as:

- increase in own weight due to additional loads that change the dynamic response of the structure and additional seismic loads;

- increasing their own weight by adding quite large loads which in the vast majority of cases require consolidation of the foundation ground;

- labor consumption;

- during consolidation the building can no longer be used;

- can change the architectural aesthetic appearance and reduce the useful space of the building

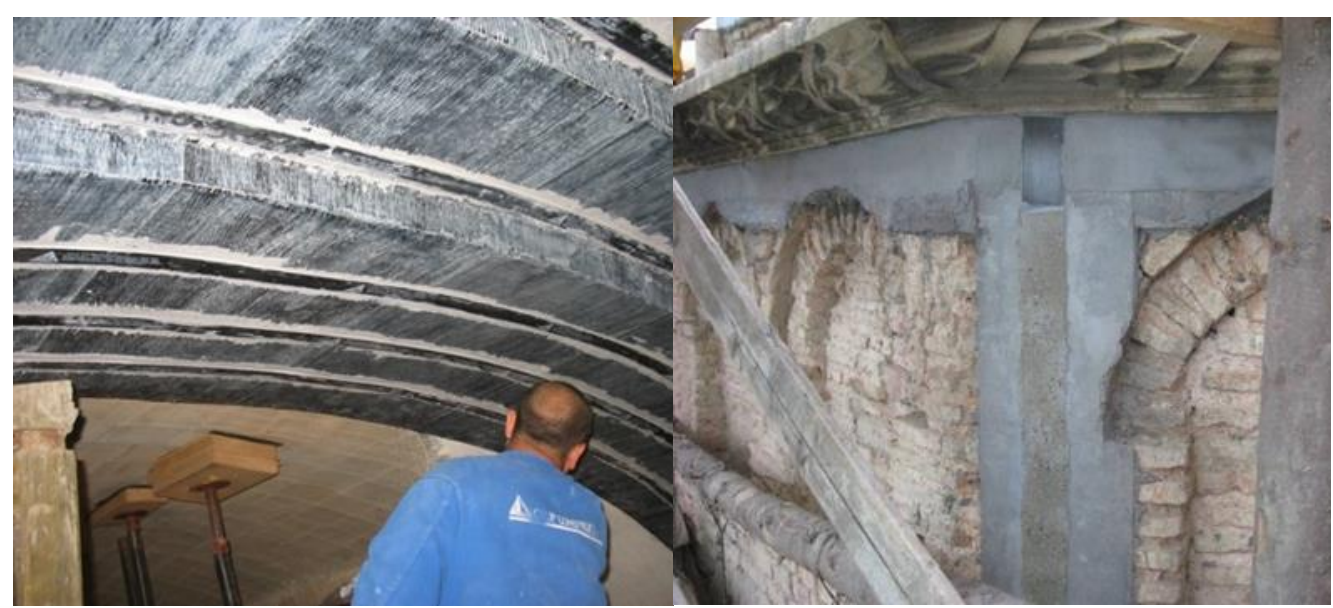

Fig. 4 Rehabilitation of arches with composite systems

Fig. 5 Rehabilitation of masonry structure with composite systems

All these disadvantages have influenced the search for alternative consolidation solutions. A first masonry consolidation solution with composite systems is in the form of a fiber fabric (glass, carbon or aramid) which is impregnated with a polymeric resin and bonded to the surface of the masonry which has been prepared. 


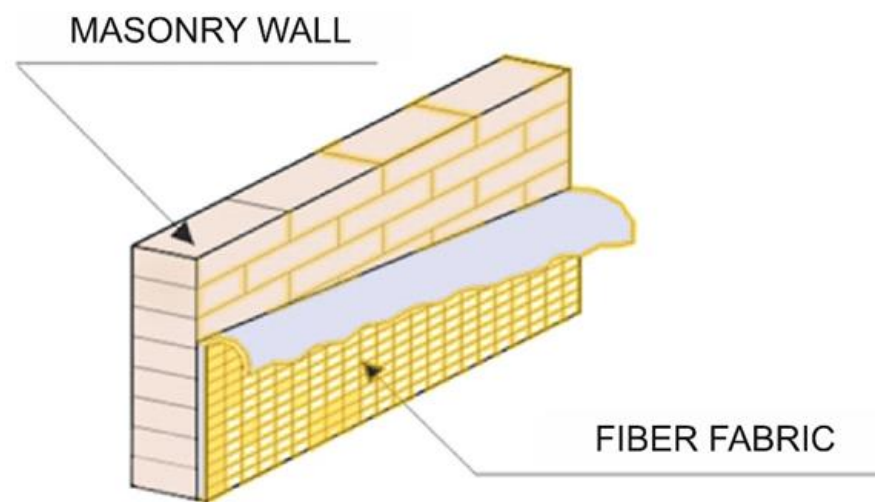

Fig. 6 Consolidation of non-reinforced masonry with composite membrane

It has been shown from the studies that the method of consolidation is more effective with narrow composite strips. Normal tensions can be much better overtaken by proper orientation of narrow composite strips than by fastening continuous fiber fabrics to the entire wall of the masonry. When the normal wall bending is the predominant load, it is necessary to use the horizontal composite strips to increase the bending capacity, and when the brick masonry is bent in its plane, it is recommended to fix the composite exterior reinforcement in the predominantly tensioned areas.

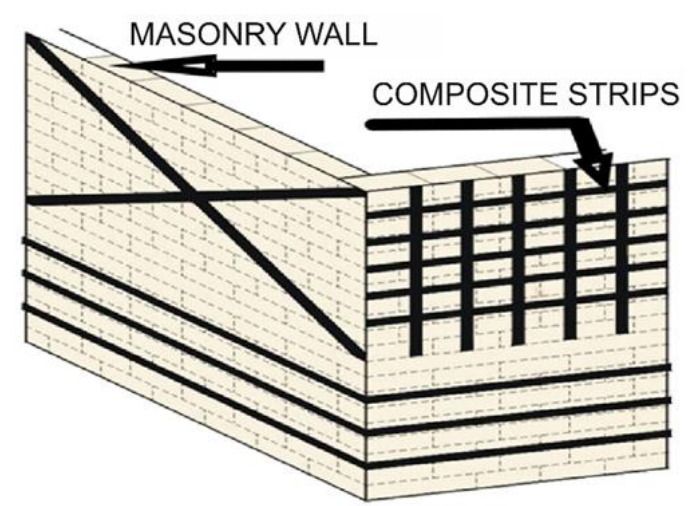

Fig. 7 Consolidation of brick walls with composite strips

As with the classic tensioning system, a maximum effect of consolidation can only be achieved if the anchoring of the composite ends at the ends is achieved by fastening systems and corresponding anchoring lengths. If the composite strips are not fixed properly, they can detach and behave just like the reinforced concrete elements in the failure stage.

Masonry historical heritage monuments can be exposed to the consolidation process with the help of perimeter rods from composite strips or round bars for horizontal tightening by tensioning. Both the composite strips and the composite round bars are unidirectionally reinforced and have very small resistances in the transverse direction. Composite systems have a number of special features in terms of splicing and anchoring due to the fact that they cannot be mechanically processed or threaded. For anchoring special devices are required to be fixed fit at the ends or in the middle. 


\section{sciendo}

Due to the fact that fiber-reinforced polymer composite lamellae cannot be bent at small angles, rods from composite systems can provide an appropriate anchorage only by means of metallic elements arranged at the corners. If it is necessary to tighten the composite rods, two brackets connected with a clamping system are used.

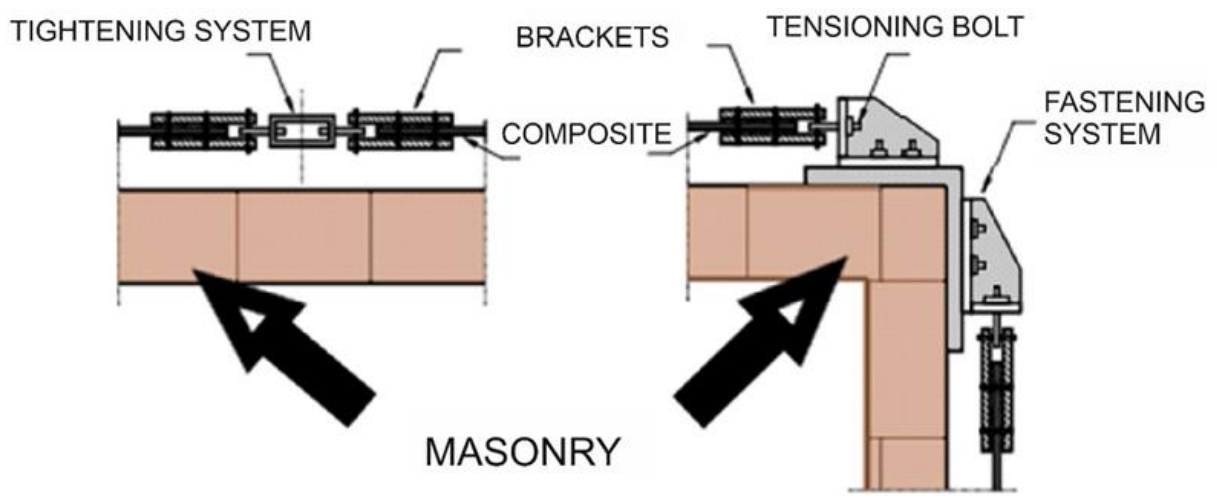

Fig. 8 Systems for fastening composite strips used to reinforce brick walls

\section{SOLUTIONS FOR THE CONSOLIDATION OF HISTORICAL WOODEN ELEMENTS}

Humans built the first houses with the materials at hand: wood and stone. Whether it was structural or closure elements (walls, roof), wood has always been an optimal solution. The concept of wood composite reinforcement is relatively new and is based on the structure consolidation technique. As concrete pillars and beams are reinforced with composite systems, the same method can be applied to wood pillars and beams to increase structural capacity.

Historic monuments and patrimony buildings are indicated for the use of composite systems for wood elements (wooden arches, wood beams, wooden bridges).
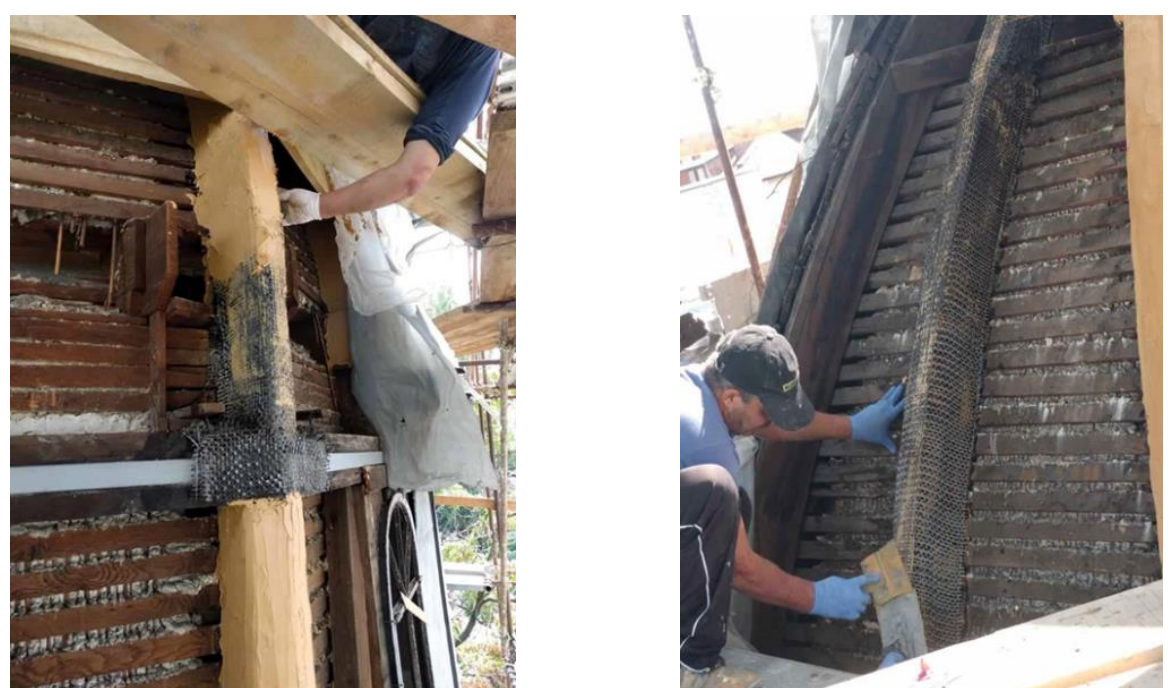

Fig. 9 Examples of consolidation of wood structures with composite systems 


\section{sciendo $_{32}$ Ovidius University Annals Series: Civil Engineering, Year 21, 2019}

The following figure exemplifies a composite reinforcement of structural wood elements:

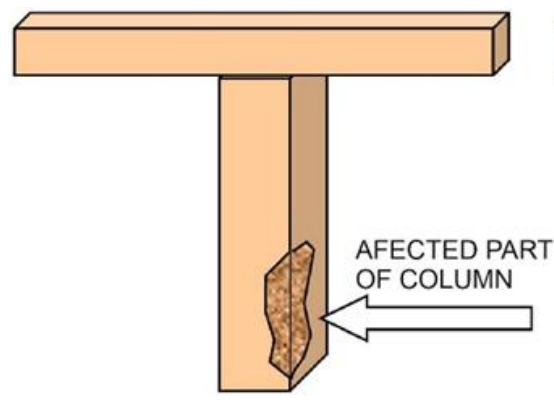

a.

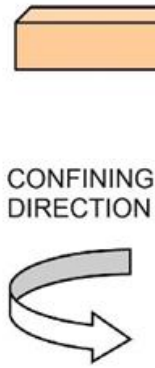

I.

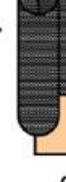

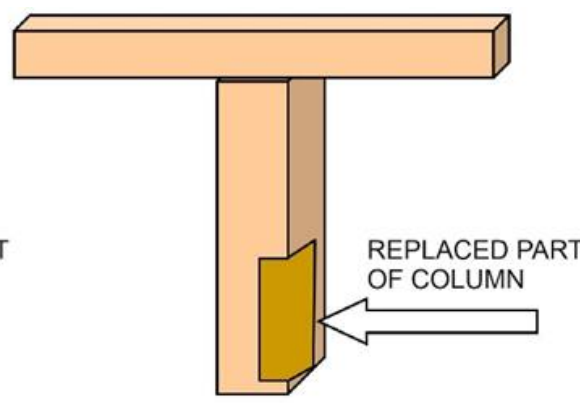

b.

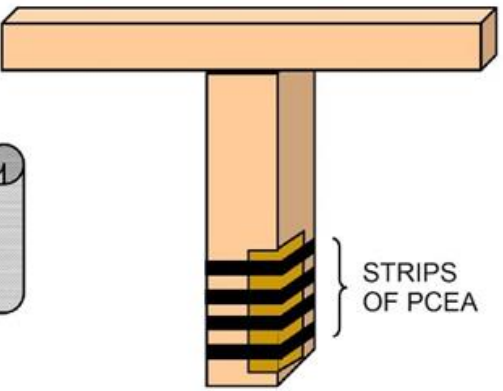

d.

Fig. 10 Strengthening wooden columns with rectangular section:

a. column affected by rotting process; $\mathbf{b}$. cutting the affected column portion and replacing the degraded part; $\mathbf{c}$. confining the wooden column using carbon fiber (I) or glass (II) fibers impregnated with epoxy resins; d. strips of Polymeric Composites bonded with Epoxy Adhesive [9]

\section{CONCLUSIONS}

The rehabilitation of historical monuments and heritage buildings is a complex challenge in all respects for engineers. In order to meet as many requirements as they face in consolidation projects, composite materials have been improved over time so that the use of composites can meet the requirements for consolidation of simple or reinforced concrete, brickwork, metal or wood structures.

The method of consolidation of heritage buildings and historical monuments must be determined upon a thorough analysis of the possibilities of intervention and the types of material accepted.

The application of composite systems in the rehabilitation of heritage buildings and historical monuments requires minimal labor. In order to apply the composite elements, it is necessary that the substrate be properly prepared, cracked and stable. In the vast majority of cases it is necessary to carry out a series of repairs of the support layer, following the application of the composite systems. In the last 20 years, the solution of structural consolidation with composite systems has become increasingly known with a wide applicability in projects aimed at improving the structure through consolidation. 
More and more cities are actively involved in the rehabilitation and conservation of heritage buildings and historical monuments by launching good practice guides. Through these guides, municipalities increasingly want to save the local cultural heritage by applying in the consolidation the most robust methods of composite elements, without the need to change the overall dimensions of the structures by a classic covering.

\section{REFERENCES}

[1] Kolsch, H. (1998). “ Carbon fiber cement matrix (CFCM) overlay system for masonry strengthening” Journal of Composites for Construction, 2(2), May, 105-109.

[2] Kurtis K.E., Dharan C.K.H. (1997). “Composite Fibers for External Reinforcement of Natural Stone." in Journal of Comp. for Construction, August

[3] Triantafillou, T. C., Fardis, N. M. (1997). "Strengthening of historic masonry structures with composite materials," Materials and Structures, vol. 30, October, 486-496.

[4] Triantafillou, T. (1998). "Strengthening of masonry structures using epoxy bonded FRP Laminates," Journal of Composites for Construction, 2(2), May, 96-104.

[5] Triantafillou T.C. (1998). "Strengthening of Structures with Advanced FRPs." In: Constr. Res. Com. Lim.

[6] Taranu N., Oprisan G., Isopescu D., Entuc, I., Munteanu, V. (2006). "Soluţii compozite de reabilitare a structurilor ingineresti", Ed. Stef, Iasi, 278pp

[7] ACI 224. 1R-84. (1984). "Causes, Evaluation and Repair of Cracks în Concrete Structures," ACI Comittee 224

[8] ACI 318-95, (1995). "Building code requirements for reinforced concrete," American Concrete Institute, Committee 318, Detroit

[9] ACI Committee 440 (2000). "Guide for the design and construction of externally bonded FRP systems for strengthening concrete structure,” January, American Concrete Institute

Note:

Vlăescu Daniel - Technical Manager S.C. Cinemx SRL, Technical Service Chief S.C. Confort Urban SRL, Strada Varfu cu Dor nr 10, Constanța, România, Tel: +40 724343956 Email: vlaescudan@yahoo.com Djordje Krkljus - Development Manager S.C. Comvex SA, Incinta Port Nou, Dana 80-84, Constanta, România, Tel: +40 722 215892, Email: djordje.krkljus@comvex.ro

Dogaru Petrișor - Manager S.C. General Construct Grup SRL, Str. Ecaterina Teodoroiu, Constanța, Tel: +40 723 621952, Email: dogaru.p@gmail.com 